\section{$\underset{\substack{\text { hommes } \\ \text { \& migrations }}}{ }$}

\section{Hommes \& migrations}

Revue française de référence sur les dynamiques

migratoires

$1324 \mid 2019$

Religion et discrimination

\title{
Gauz, Camarade Papa
}

Paris, Le nouvel Attila, 2018, 256 pages, 19 euros

\section{Marie Poinsot}

\section{(2) OpenEdition \\ 1 Journals}

\section{Édition électronique}

URL : https://journals.openedition.org/hommesmigrations/8915

DOI : 10.4000/hommesmigrations.8915

ISSN : 2262-3353

\section{Éditeur}

Musée national de l'histoire de l'immigration

\section{Édition imprimée}

Date de publication : 1 janvier 2019

Pagination : 173-174

ISBN : 978-2-919040-44-5

ISSN : 1142-852X

\section{Référence électronique}

Marie Poinsot, «Gauz, Camarade Papa », Hommes \& migrations [En ligne], 1324 | 2019, mis en ligne le

01 janvier 2019, consulté le 07 janvier 2022. URL : http://journals.openedition.org/

hommesmigrations/8915; DOI : https://doi.org/10.4000/hommesmigrations.8915 


\section{Gauz}

\section{Camarade Papa}

Paris, Le nouvel Attila, 2018, 256 pages, 19 euros.

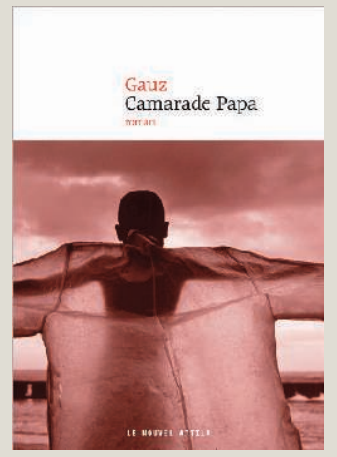

Le premier roman de Gauz, Debout-Payé (Le nouvel Attila, 2014), avait été un vrai succès littéraire couronné de nombreux prix. À travers les aventures dans les années 1990 de Ossiri, étudiant ivoirien devenu vigile, le roman, à la croisée de la sociologie et du romanesque, faisait du poste de surveillance d'un vigile le point d'observation de la société de consommation (les chaînes de l'habillement et de la beauté) et le point de départ d'un parcours dans la communauté africaine de Paris, de l'intérieur.

Après quatre années d'attente, Camarade Papa propose une fresque qui embrasse à la fois l'épopée coloniale et les migrations militantes des années 1970. Et les contes et légendes africaines qui scandent le roman. On chemine de la Hollande à la Côte d'Ivoire 
en passant par le centre de la France. Ce roman en ellipse est construit sur deux périodes, autour du voyage de deux personnages principaux: Maxime Dabilly, un jeune homme issu du petit village d'Abilly, à la fin du XIXe siècle, perd sa mère, migre vers Châtellerault où il travaille un temps dans la manufacture d'armes (la «Manu»), avant de rejoindre La Rochelle et de s'embarquer pour l'Afrique. "Seul, en bande ou avec tout un peuple, de la Genèse à l'Apocalypse, on part pour se sauver, accomplir une destinée. » À travers son périple, le roman présente une exploration inédite de la colonisation en Afrique qui s'illustre par la conquête de territoires et de richesses sous la pression de la concurrence des autres entreprises coloniales, belge et britannique, pour la domination des peuples. Un enfant, qui vit dans le quartier populaire et «rouge» de la prostitution d'Amsterdam dans une famille communiste, est envoyé en Afrique, après le décès de sa mère, auprès de sa grand-mère. Son père souhaite ainsi qu'il renoue avec ses origines lointaines, avec ses ancêtres, sa culture et sa langue. La boucle est bouclée quand on découvre la relation familiale qui lie les deux protagonistes sur un siècle.

La genèse de Camarade Papa est une idée ancienne que Gauz a pris le temps de mûrir. L'ambition était visiblement d'écrire l'histoire de la colonisation avec un récit d'un nouveau genre, tout en montrant ses effets et ses prolongations dans l'histoire contemporaine. "L'ethnologie de GrandBassam est complète. » Des histoires dans la complexité de leur dimension humaine, en illustrant aussi bien le roman pour dénoncer le projet impérial de conquête politicoéconomique, mais aborder également ce que la colonisation a suscité comme rencontres, découvertes de personnalités, dont le portrait truculent est une grande richesse romanesque - et leur racialisation -, mais aussi métissages de populations et de cultures. Ce roman joue ainsi sur les points de vue: celui d'un colonisateur blanc qui croise celui d'un enfant métisse quelques générations plus tard. Ces histoires entremêlées présentent plusieurs facettes contradictoires de la colonisation, et les influences culturelles et identitaires qui en découlent et lient l'Europe et l'Afrique.

Plus globalement, Camarade Papa montre comment des voyages s'inscrivent dans la grande histoire des migrations humaines.
Ainsi, il brasse dans un même récit l'exode rural et autres migrations internes en France après la défaite de Sedan en 1871 contre les Prussiens, et celles liées à l'industrialisation et à l'urbanisation de la France. Sans oublier les migrations liées à des engagements militants: les voyages entre pays communistes «frères» et, enfin, les migrations de conquête territoriale des colonisateurs. Ce roman nous dit que ces migrations sont connectées sans être comparables et inscrites dans l'universalité des mobilités humaines.

Le roman joue également sur l'invention de plusieurs langages qui construisent des personnages hauts en couleur. Ces registres langagiers sont multiples: le choix de la voix de l'enfant qui permet de mettre à distance le monde des adultes vus à hauteur d'un enfant bilingue; le langage révolutionnaire du père nous entraîne dans l'univers disparu des «camarades rouges»; sans parler des inventions linguistiques autour des langues de ceux qui partent en Afrique à la fin du XIXe siècle et des populations qu'ils rencontrent sur place. Les langues du roman déploient ainsi des échanges, des univers sonores, émotionnels, et des passerelles entre des cultures différentes. Le style du roman mêle profondeur du propos étayé par une documentation historique que l'on pressent très solide, inventivité des situations, et profusion des personnages, des événements et des découvertes. Il mobilise l'humour pour faciliter la subversion des codes et des autorités. Les critiques ont salué la prouesse de l'écriture de Gauz dans sa capacité à ramasser des histoires et des mondes pluriels dans une même narration. "Ce deuxième roman enfonce le clou d'un majestueux coup de marteau (et de faucille)» conclut Esprit Livres à Lyon. On peut dire que Camarade Papa vivifie la littérature contemporaine par son ambition et ses inventions narratives et stylistiques. Le roman permet de s'extraire des ghettos thématiques de l'exil comme expérience de domination et de posture victimaire, et pose un autre regard sur l'Afrique et son histoire, valorisant les savoirs, les pratiques sociales, les traditions et les imaginaires, etc.

Marie Poinsot 